\title{
The antitumor efficacy of monomeric disintegrin obtustatin in S-180 sarcoma mouse model
}

\author{
Narine Ghazaryan ${ }^{1,2} \cdot$ Naira Movsisyan $^{2,3} \cdot$ Joana Catarina Macedo $^{4} \cdot$ Sara Vaz $^{4} \cdot$ Naira Ayvazyan $^{1} \cdot$ Luis Pardo $^{2}$. \\ Elsa Logarinho ${ }^{4}$
}

Received: 10 December 2018 / Accepted: 18 January 2019

(C) Springer Science+Business Media, LLC, part of Springer Nature 2019

\begin{abstract}
Summary
Obtustatin, isolated from the Levantine Viper snake venom (Macrovipera lebetina obtusa -MLO), is the shortest known monomeric disintegrin shown to specifically inhibit the binding of the $\alpha 1 \beta 1$ integrin to collagen IV. Its oncostatic effect is due to the inhibition of angiogenesis, likely through $\alpha 1 \beta 1$ integrin inhibition in endothelial cells. To explore the therapeutic potential of obtustatin, we studied its effect in S-180 sarcoma-bearing mice model in vivo as well as in human dermal microvascular endothelial cells (HMVEC-D) in vitro, and tested anti-angiogenic activity in vivo using the chick embryo chorioallantoic membrane assay (CAM assay). Our in vivo results show that obtustatin inhibits tumour growth by $33 \%$. The expression of vascular endothelial growth factor (VEGF) increased after treatment with obtustatin, but the level of expression of caspase 8 did not change. In addition, our results demonstrate that obtustatin inhibits FGF2-induced angiogenesis in the CAM assay. Our in vitro results show that obtustatin does not exhibit cytotoxic activity in HMVEC-D cells in comparison to in vivo results. Thus, our findings disclose that obtustatin might be a potential candidate for the treatment of sarcoma in vivo with low toxicity.
\end{abstract}

Keywords Obtustatin $\cdot$ Sarcoma $\cdot$ Angiogenesis $\cdot$ VEGF

\section{Introduction}

Soft tissue sarcomas (STS) are rare malignant tumors deriving from cells of mesenchymal origin (bone, muscle, fat) [13]. They can occur anywhere in the body, but they develop

Electronic supplementary material The online version of this article (https://doi.org/10.1007/s10637-019-00734-2) contains supplementary material, which is available to authorized users.

Narine Ghazaryan

naringhazaryan@gmail.com

1 Laboratory of Toxinology and Molecular Systematics, L.A. Orbeli Institute of Physiology, 0028 Yerevan, Armenia

2 Oncophysiology Group, Max Planck Institute for Experimental Medicine, 37075 Göttingen, Germany

3 Göttingen Graduate School for Neurosciences, Biophysics, and Molecular Biosciences, Göttingen, Germany

4 Aging and Aneuploidy Laboratory, Instituto de Biologia Molecular e Celular, Instituto de Investigação e Inovação em Saúde - i3S, Universidade do Porto, Rua Alfredo Allen 208, 4200-135 Porto, Portugal more frequently in the extremities, retroperitoneum and neck $[9,10]$. More than 50 histological types of STS are known, the most common being leiomyosarcoma, malignant fibrous histiocytoma, liposarcoma, synovial sarcoma, fibrosarcoma and malignant peripheral nerve sheath tumors [9].

Tumor growth and metastasis require angiogenesis, which is defined as the development of new blood vessels from a pre-existing vascular bed $[3,14,15]$. Vascular endothelial growth factor (VEGF-A) plays a core role as a mediator of angiogenesis. Different in vivo studies using murine tumor models of STS have shown overexpression of VEGF-A. When the murine T241 fibrosarcoma cell lines, engineered to stably overexpress VEGF-A, were implanted into immunodeficient mice to generate xenografts, VEGF-A expressing tumors displayed not only significantly accelerated growth compared with the non-VEGF expressing counterparts, but also increased tumor vessels density [2]. In another murine model of fibrosarcoma, tumors proved to be very invasive in vivo and exhibited highly irregular vessels, variable in shape and diameter and showed high levels of VEGF-A [21].

The fast vascularization process during tumor progression leads to the formation of pathological vessels formed by 
improperly organized endothelial cells [7, 20]. To date, many anti-angiogenic drugs have been developed, but their therapeutic efficacy is limited and often associated with toxic side effects. The obtustatin isolated from the snake venom of Macrovipera lebetina obtusa (MLO) represents the shortest known KTS (Lys-Thr-Ser) monomeric disintegrin so far [5, 24, 27-29, 34]. Therapeutic effectiveness of obtustatin was particularly remarkable in the experiments on mice, but only in the case of intravascular (i.v.) administration [4]. This low molecular weight peptide revealed a potent therapeutic effect on melanoma progression and recently we have shown its inhibitory effect on S-180 sarcoma bearing mouse model [16]. Its oncostatic effect is due to the inhibition of angiogenesis, which possibly arises from $\alpha 1 \beta 1$ integrin inhibition in the endothelial cells [4].

Integrins are a family of receptors expressed on the cell surface, which adhere to multiple ligands and mediate cellcell and cell-extracellular matrix interactions. These transmembrane glycoproteins are composed of two noncovalently linked subunits $-\alpha$ and $\beta .8 \beta$ subunits can assort with $18 \alpha$ subunits to form 24 distinct integrins, which are widely distributed in mammalian cells. Among them, the collagen receptors are the functional subclass specifically interacting with distinct types of collagens. The $\alpha 1, \alpha 2, \alpha 10$ or $\alpha 11$ subunits of collagen receptors associate with the $\beta 1$ subunit to make an active complex on the cell surface. The $\alpha 1 \beta 1$ integrin is a specific receptor for collagen type IV and $\alpha 2 \beta 1$ for collagen type I with an IC50 of $2 \mathrm{nM}$ and $0.5 \mathrm{nM}$, respectively [4, 28, 29, 37]. These integrins are highly up-regulated by the sVEGF in cultured endothelial cells, resulting in enhanced spreading of collagen and supporting VEGF signaling, endothelial cell migration, and tumor angiogenesis $[6,7,12,15,26,30,35]$.

The anti-angiogenic activity of obtustatin as well as its inhibitory effect on experimental tumor growth have previously been reported $[4,27,29]$. In this paper, the functions and mechanisms of obtustatin in sarcoma angiogenesis are presented for the first time. We have demonstrated the influence of obtustatin on the VEGF expression using the S-180 sarcoma bearing mouse model, we have also examined the expression of several caspases by Western blot. We revealed that obtustatin did not induce any signs of apoptotic death in the sarcoma treated animals and we also found no evidence of activation of caspase 8, as previously described for integrin-mediated death (IMD) [36]. In addition, we explored the anti-angiogenic effect of obtustatin using the chick embryo chorioallantoic membrane in vivo assay (CAM assay) and human dermal microvascular endothelial cells (HMVEC-D) in vitro. Our results have demonstrated a lack of cytotoxic effect of obtustatin in HMVEC-D cells in vitro even for the extremely high concentrations, which is a striking contrast with the previous study [4].

\section{Materials and methods}

\section{Chemicals}

Obtustatin isolated from the $M L O$ snake venom was purchased from Tocris (Cat. N 4664, Bristol, United Kingdom). The purity of obtustain is $95.6 \%$ according to the HPLC and MS analysis of the protein (https://documents.tocris.com/ pdfs/tocris_coa/4664_3_coa.pdf?1546428880). Primary adult human dermal microvascular endothelial cells (HMVEC-D) were purchased from ATCC (Manassas, USA) and cultured in complete endothelial cell basal 131 medium supplemented with microvascular growth supplement (MVGS) containing 15\% FBS (all from Invitrogen, Carlsbad, USA). Early passage [3-6] HMVEC-D cells were used in all experiments. The recombinant human vascular endothelial growth factor (VEGF) and collagen IV were obtained from Sigma (St. Louis, USA); the fibroblast growth factor (FGF2) was purchased from Immuno Tools (Friesoythe, Germany).

\section{Tissue lysis}

The tumour tissues were lysed with an addition of $2 \mathrm{ml}$ of the lysis buffer $(0.5 \%$ Triton X-100; $25 \mathrm{mM}$ Tris-HCl pH 7.5; $75 \mathrm{mM} \mathrm{NaCl} ; 2.5 \mathrm{mM}$ EDTA, pH 8.0; $0.5 \mathrm{mM}$ PMSF; $0.5 \mathrm{mM}$ DTT; $5 \mathrm{mM} \mathrm{NaF}$; cocktail of protease inhibitor (Roche)). To homogenize the tissues and allow high yield of protein from the tissues, a bead was added to the samples with the lysis buffer, and the samples were vigorously agitated at a frequency of 30 beats per second for $3 \mathrm{~min}$ at room temperature (RT). If some pieces of tissue were still visible in the samples, the homogenization step was repeated. Afterwards, the homogenized samples were centrifuged at $15000 \mathrm{rpm}$, 30 min at RT. If the resulting supernatant was still turbid, the centrifugation step was repeated. Afterwards, the supernatant was recovered.

\section{Protein concentration measurement. SDS-PAGE. Western blot. Densitometry analysis}

Concentration of proteins in the tissue lysates was determined by BCA Protein Assay Kit. In order to disrupt protein secondary structure and allow proteins to migrate depending on the mass to charge ratio during sodium dodecyl sulphate polyacrylamide gel electrophoresis (SDS-PAGE), NuPAGE reducing agent (Invitrogen), and NuPAGE LDS Sample buffer (Invitrogen) were added to the samples (50 $\mu \mathrm{g}$ total protein) in 1:10 and 1:4 ratio to the final volume, respectively. The reduced samples were incubated at $70{ }^{\circ} \mathrm{C}$ for $10 \mathrm{~min}$. The denatured samples $(50 \mu \mathrm{g})$ were resolved on $4-12 \%$ NuPAGE Novex Bis-Tris Mini Gels (Invitrogen) in MOPS buffer at $180 \mathrm{~V}$. To estimate the molecular weight of protein 
of interest, ColorPlus pre-stained protein ladder (BioLabs) was used.

Once protein samples were separated by SDS-PAGE, proteins were transferred onto a nitrocellulose membrane (NC) (Novex, $0.2 \mu \mathrm{m}$ ) using Pierce Power Blot Station and Blotting Cassette (Thermo Scientific) at a voltage of $25 \mathrm{~V}$ and a current of $3 \mathrm{~A}$ for $13 \mathrm{~min}$. Following the transfer, the NC membranes were rinsed with deionized water and treated with western signal enhancer (Thermo Scientific) according to the manufacturer's instructions. To prevent non-specific binding of the antibody probes to the membrane surface, the membrane was then incubated for $1.5 \mathrm{~h}$ in blocking buffer containing $0.1 \%$ casein (Roche) in TBS (0.1\% Tween 20$)$.

To identify VEGF and caspases, the NC membranes were incubated with a primary antibody against VEGF and caspase 8 (1:1000, sc-7269, Santa Cruz), procaspase 9 (1:500, sc133109, Santa Cruz), cleaved caspase 3 (1:1000, \#9661S, Cell Signaling), caspase 5 (1:500, sc393346, Santa Cruz) in blocking buffer with gentle agitation overnight at $4{ }^{\circ} \mathrm{C}$. After 5 washes with deionized water and 5 min incubation with TBS$\mathrm{T}$, the membranes were incubated for $1 \mathrm{~h}$ at RT with horseradish peroxidase (HRP) conjugated anti-mouse secondary antibody in blocking buffer (1:8000, NA931, GE Healthcare). Then the membranes were washed 7 times with deionized water and incubated for $5 \mathrm{~min}$ in TBS-T. At last, the chemiluminescent HRP substrate (Millipore) was applied to the blots for $5 \mathrm{~min}$, initiating the chemiluminescence reaction catalyzed by the peroxidase conjugated to the secondary antibody. The emitted light was detected with a ChemiDoc XRS system (Bio-Rad), the image acquisition was done using Quantity One 1-D Analysis software v4.6.9 (Bio-Rad). For image processing and analysis ImageLab 4.0 software was used (Bio-Rad).

After detection of the corresponding chemiluminescence signal, the membranes were stripped and re-probed. The NC membranes were first washed with TBS-T and then incubated for $30 \mathrm{~min}$ at $37{ }^{\circ} \mathrm{C}$ in sufficient volume of Restore Plus Western Blot stripping buffer (Life technologies) to ensure that the blot was completely wetted (i.e. approximately $20 \mathrm{~mL}$ for an $8 \times 10 \mathrm{~cm}$ blot). The complete removal of the enzyme conjugate was tested by an additional incubation with a new aliquot of HRP chemiluminescence substrate working solution. If no signal was detected using a minimum $5 \mathrm{~min}$ exposure, the enzyme conjugate was successfully removed from the antigen or primary antibody. The membranes were incubated with an anti-actin antibody (1:1000; sc-1615) for $2 \mathrm{~h}$ at RT and secondary anti-goat antibody $(1: 10000 ; 172-$ 1034, Bio-Rad) for $1 \mathrm{~h}$, preceded by a blocking step as described above. All the steps during this part of the procedure were carried out at RT and with gentle agitation.

The detected chemiluminescence was used to assess the changes in the expression of the protein of interest by densitometric analysis with the BIO-RAD Image Lab 4.0 software.
Therefore, the volume intensity of each Western Blot signal was measured after selecting the corresponding band with the 'Lane and Bands' tool and adjusting the chosen area using the 'Lane profile'. The background was subtracted by rolling disk subtraction method (disk size $8 \mathrm{~mm}$ ). The molecular weight was determined with the ' $\mathrm{MW}$ ' analysis tool. The normalized volume intensity of each signal was then calculated by dividing its measured volume intensity by the corresponding actin value.

\section{S-180 sarcoma mouse model and administration}

The S-180 sarcoma cells were transplanted subcutaneously into the right axilla of each mouse. When the tumor grew to $100-300 \mathrm{~mm}^{3}$ we randomly divided mice into 2 groups: model (tumor control), and S-180 sarcoma group treated with obtustatin. Each group contained 5 mice. The mice were administered as follows: model group, PBS; obtustatin treated group, $1 \mathrm{mg} / \mathrm{kg}$ body weight obtustatin. All the solutions were dissolved in PBS and administered daily by an intra-tumor injection $(50 \mu \mathrm{l})$ for 5 days. Twenty-four hours after the last drug administration, all the animals were weighed and sacrificed by cervical dislocation. All the procedures were done according to our institution's animal care rules and the IACUC's ethical guidelines for Decapitation of Unanesthetized Mice and Rats (http:/www.utsouthwestern. edu/utsw/cda/dept238828/files/ 469,088.html).

\section{Antitumor activity assay in vivo}

The antitumor activity was expressed as inhibitory rate (\%) and was calculated as $[(\mathrm{A}-\mathrm{B}) / \mathrm{A}] * 100 \%$, where $\mathrm{A}$ and $\mathrm{B}$ was the average tumor weight of the model and that of the treated group, respectively.

\section{Chick embryo chorioallantoic membrane assay (CAM assay)}

The CAM assay was used to evaluate the anti-angiogenic activity of obtustatin. Fertilized chick (Gallus gallus) eggs obtained from commercial sources were incubated horizontally at $37.8^{\circ} \mathrm{C}$ in a humidified atmosphere and referred to by embryonic (E). On E3, a square window was opened in the shell after removal of 2-2.5 $\mathrm{ml}$ of albumen to allow detachment of the developing CAM. The window was sealed with transparent adhesive tape and the eggs returned to the incubator. Testing conditions were placed on top of E10 growing CAM into a $3 \mathrm{~mm}$ silicone ring under sterile conditions: bFGF2 (400 ng/egg; ImmunoTools) was used as an angiogenesis inducer in the control group $(N=13)$ and bFGF2 (400 ng/ egg) and obtustatin $(90 \mu \mathrm{M})$ in the test group $(N=16)$. The eggs were re-sealed and returned to the incubator for an additional $72 \mathrm{~h}$. Three independent experiments were performed. 
After removing the ring, the CAM was excised from the embryos, and photographed ex ovo under a stereoscope using 20x magnification (Olympus, SZX16 coupled with a DP71 camera). The number of new vessels (less than $15 \mu \mathrm{m}$ diameter) growing radially towards the ring area was quantified blindly.

\section{IncuCyte Cytotox green detection of cell death}

The IncuCyte Cytotox green reagent was used according to the manufacturer's instructions for quantifying dead cells after $24 \mathrm{~h}$ treatment with obtustatin $(90 \mu \mathrm{M})$. The experiments were performed in triplicates. Obtustatin was diluted in PBS 1x. HMVEC-D cell proliferation was induced with $50 \mathrm{ng} / \mathrm{ml} \mathrm{hu-}$ man recombinant VEGF.

\section{Cell viability and apoptosis assay}

Cell viability and apoptosis were quantified using the ApoLive-Glo multiplex Assay (Promega, Fitchburg, USA) according to the manufacturer's instruction, after a $24 \mathrm{~h}$ treatment with obtustatin $(90 \mu \mathrm{M})$. Experiments were performed in triplicates and data were plotted as an average \pm standard error of the mean. Obtustatin was diluted in PBS 1x. HMVEC-D cell proliferation was induced with $50 \mathrm{ng} / \mathrm{ml} \mathrm{hu-}$ man recombinant VEGF.

\section{Results}

\section{Obtustatin inhibited the growth of S-180 sarcoma in mice, increased VEGF expression and didn't change caspase 8, 9, 5 and 3 expression}

To test the effects of obtustatin on tumor growth in vivo, we injected sarcoma cells subcutaneously into the right axilla of mice. When the tumor size reached $100-300 \mathrm{~mm}^{3}$, the mice were randomly divided into 2 groups that were treated daily by intratumoral injection of $50 \mu \mathrm{l}$ of either vehicle (PBS) or obtustatin $(1 \mathrm{mg} / \mathrm{kg})$ for 5 days. Twenty-four hours after the last drug administration, all the animals were weighed and sacrificed by cervical dislocation. The tumors were excised and weighted. Figure 1 compares the percent rate of inhibition of the tumors between PBS and obtustatin-treated mice. Tumors treated with obtustatin showed 33\% lower weight than controls, indicating that obtustatin inhibits the growth of sarcoma S-180 cells in vivo.

Furthermore, there was no significant weight loss in the treated group, indicating that no significant toxicity was induced by obtustatin treatment (data not shown).

Reduction of tumor growth can have multiple causes, from direct inhibition of cell proliferation to reduced supply of nutrients and oxygen due to defective vascularization. Defects in

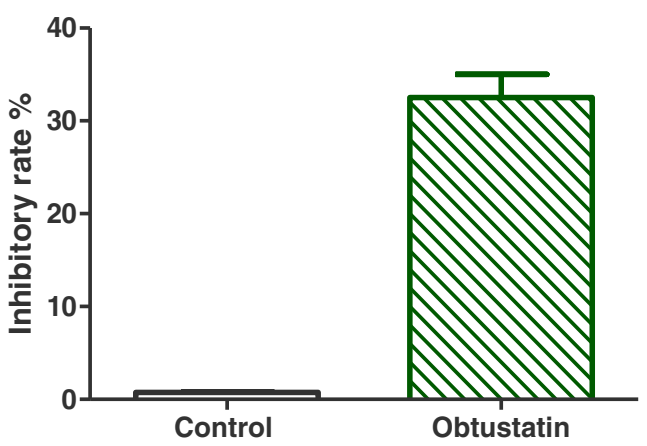

Fig. 1 Effective suppression of sarcoma growth in S-180 bearing mice was induced by obtustatin. After the sarcomas had reached $100-300 \mathrm{~mm}^{3}$ in volume mice were randomly subdivided into 2 groups: model (tumor control), and S-180 sarcoma group treated with obtustatin. Each group contained 5 mice. The mice were administered as follows: model group, PBS; obtustatin treated group, $1 \mathrm{mg} / \mathrm{kg}$ body weight obtustatin. Obtustatin was dissolved in PBS and administered daily by an intra-tumor injection $(50 \mu \mathrm{l})$ for 5 days. Twenty-four hours after the last drug administration, all the animals were weighed and sacrificed by cervical dislocation. The antitumor activity was expressed as inhibitory rate (\%) and was calculated as $[(\mathrm{A}-\mathrm{B}) / \mathrm{A}] * 100 \%$, where $\mathrm{A}$ and $\mathrm{B}$ was the average tumor weight of the model and that of the treated groups, respectively. The average inhibitory rate of obtustatin based on two replicates was $32.5 \%$ (95\% CI $=[27.5-$ $37.5])$. This was significantly greater than the $0.75 \%(95 \% \mathrm{CI}=[0.65$ $0.85])$ inhibitory rate of the control $(\mathrm{t}=12.70, \mathrm{df}=2, p=0.0031)$. This indicates that obtustatin inhibits the growth of sarcoma S-180 cells in vivo. The obtained values are plotted in the graph (experimental repeats -2 , mean \pm sem; unpaired $t$-test, $* * p<0.05$ )

angiogenesis can also be due to impaired production of vascular endothelial growth factor (VEGF), the major angiogenesis promoting signal. To test for this possibility, we investigated the effect of obtustatin on the expression of VEGF by Western blot, which revealed that the S-180 sarcomas treated with obtustatin had a higher, rather than lower, content of VEGF (Fig. 2),

We have previously reported that obtustatin induces necrosis and necroptosis in S-180 cell sarcomas in vivo, but we could not attribute cell death to necrosis. Brown et al. [4] have also reported that obtustatin is a potent inducer of the extrinsic pathway of apoptosis in endothelial cells. We therefore analyzed the expression of caspases 3, 5, 8 and 9 in the treated tumors, but were unable to detect any effect of obtustatin treatment on caspase levels. This strongly indicates that the reduced tumor growth does follow on from increased apoptosis of tumor or stromal cells (Fig. 2).

\section{Anti-angiogenic effect of obtustatin}

The anti-angiogenic effect of obtustatin was evaluated using the in vivo CAM assay. To mimic a pathological condition in which angiogenesis is exacerbated, we used FGF2 to stimulate vessel growth. 10 day-old chick embryos were treated with FGF2 alone, or in combination with obtustatin $(90 \mu \mathrm{M})$ $72 \mathrm{~h}$ after the treatment, the CAM were excised from the embryos, photographed ex ovo under a stereoscope, and 


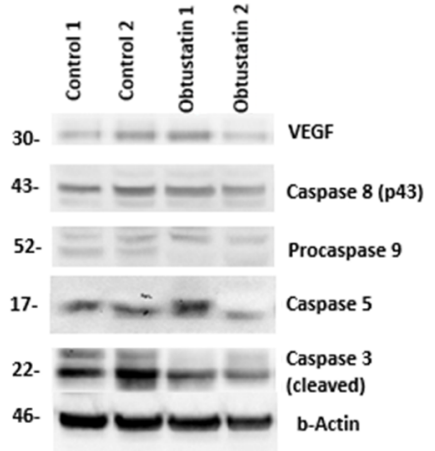

Fig. 2 Western blot analysis of VEGF and caspase 8, procaspase 9, caspase 3 , caspase 5 after treatment with obtustatin. After the sarcomas had reached $100-300 \mathrm{~mm}^{3}$ in volume mice were randomly subdivided into 2 groups: model (tumor control), and S-180 sarcoma group treated with obtustatin. Obtustatin was dissolved in PBS and administered daily by an intra-tumor injection $(50 \mu \mathrm{l})$ for 5 days. Twenty-four hours after the last drug administration, all the animals were weighed and sacrificed by cervical dislocation.

quantified for the number of new vessels $(<15 \mu$ m diameter $)$ (Fig. 3). We found a significantly lower number of new vessels in case of obtustatin treatment (Fig. 3).

\section{Effect of obtustatin in cell viability and apoptosis of HMVEC-D cells in vitro}

We next used live cell imaging in an IncuCyte system to study the effects of obtustatin on the viability of HMVEC-D cells in culture. Cell death was detected using Cytotox green, which specifically binds to DNA of dead cells due to the loss of membrane integrity. HMVEC-D cells were grown in the presence of hrVEGF in plates coated with collagen IV, which specifically activates $\alpha 1 \beta 1$ integrin signaling. The cells were
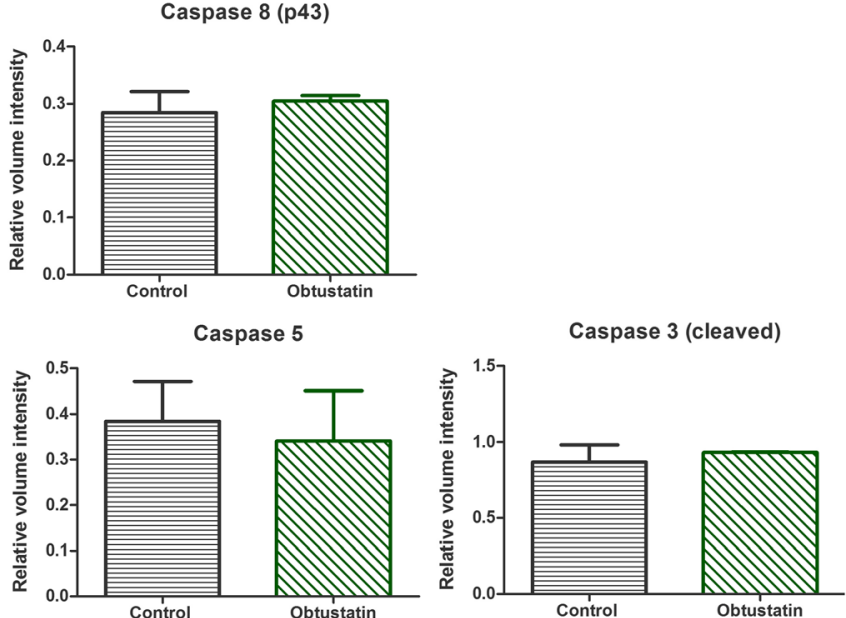

Proteins were extracted from the isolated tumours from S-180 sarcoma bearing mice and applied to Western Blot analysis. The representative Western blot images are given (anti-VEGF, caspase 8, procaspase 9, caspase 3 , caspase $5, \beta$-actin was used as a loading control). The densitometry analysis was carried out using ImageLab 4.0 software (Bio-Rad), and the obtained values are plotted in the graph (experimental repeats -2 , technical repeats -3 ; mean \pm sem; unpaired $t$-test, $* p<0.05$ )

treated with obtustatin and imaged for $24 \mathrm{~h}$ in the continuous presence of the disintegrin. As shown in Fig. 4, cell death was hardly detectable in control or obtustatin treated cells. It is noteworthy that obtustatin, even at extremely high concentrations $(90 \mu \mathrm{M})$, and under cell culture conditions that ensured activation of the $\alpha 1 \beta 1$ integrin signaling targeted by obtustatin, didn't compromise the cell viability (see also Supplementary Movies 1-2).

To quantify cell viability and apoptosis following the $24 \mathrm{~h}$ treatment with obtustatin we used the ApoLive-Glo multiplex Assay. This assay measures the activity of a protease marker of cell viability that is restricted to intact viable cells. A small peptide GF-AFC is used as a substrate for live cell protease activity, generating a fluorescent signal proportional to the

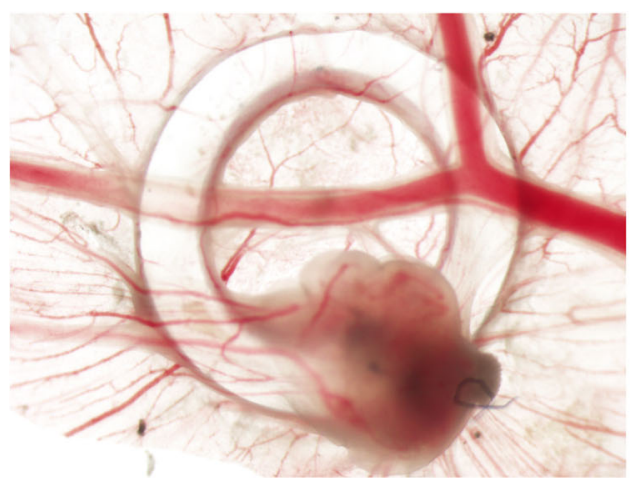

a

Fig. 3 CAM assay for the in vivo anti-angiogenic effect of obtustatin. Testing conditions were placed in a $3 \mathrm{~mm}$ silicone ring on top of E10 growing CAM under sterile conditions: (a) bFGF2 (400 ng/egg) $(N=$ 13); (b) bFGF2 (400 ng/egg) Obtustatin $(90 \mu \mathrm{M})(N=16)$. Figures are representative images of each experimental condition following $72 \mathrm{~h}$

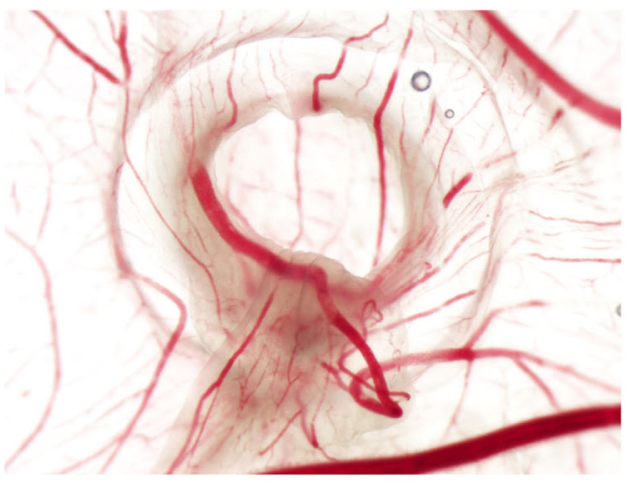

b

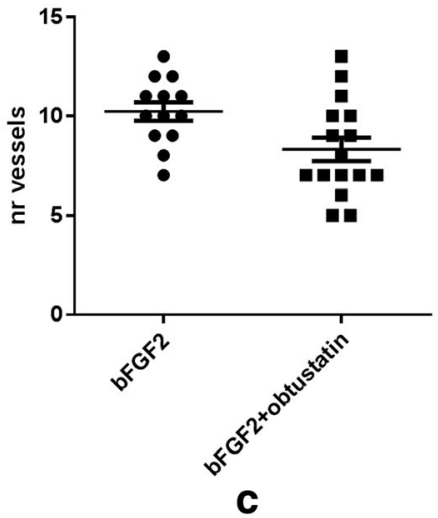

C

treatment. C) The number of new vessels $(<15 \mu \mathrm{m}$ diameter) growing radially towards the ring area was quantified blindly for three independent experiments. The obtained values are plotted in the graph (experimental repeats -3 , mean \pm sem; unpaired $t$-test, $* p<0.05$ ) 
Fig. 4 IncuCyte ZOOM® analysis for HMVEC-D cell death induced by obtustatin. HMVEC-D cells were grown in plates coated with collagen IV $(50 \mu \mathrm{g} / \mathrm{ml})$ and in the presence of hrVEGF $(50 \mathrm{ng} / \mathrm{ml})$. IncuCyte ${ }^{\circledR}$ Cytotox green $(0.25 \mu \mathrm{M})$ was added after a $24 \mathrm{~h}$ treatment with obtustatin $(90 \mu \mathrm{M})$. The representative field images were acquired with IncuCyte ZOOM®. Scale bar, $300 \mu \mathrm{m}$

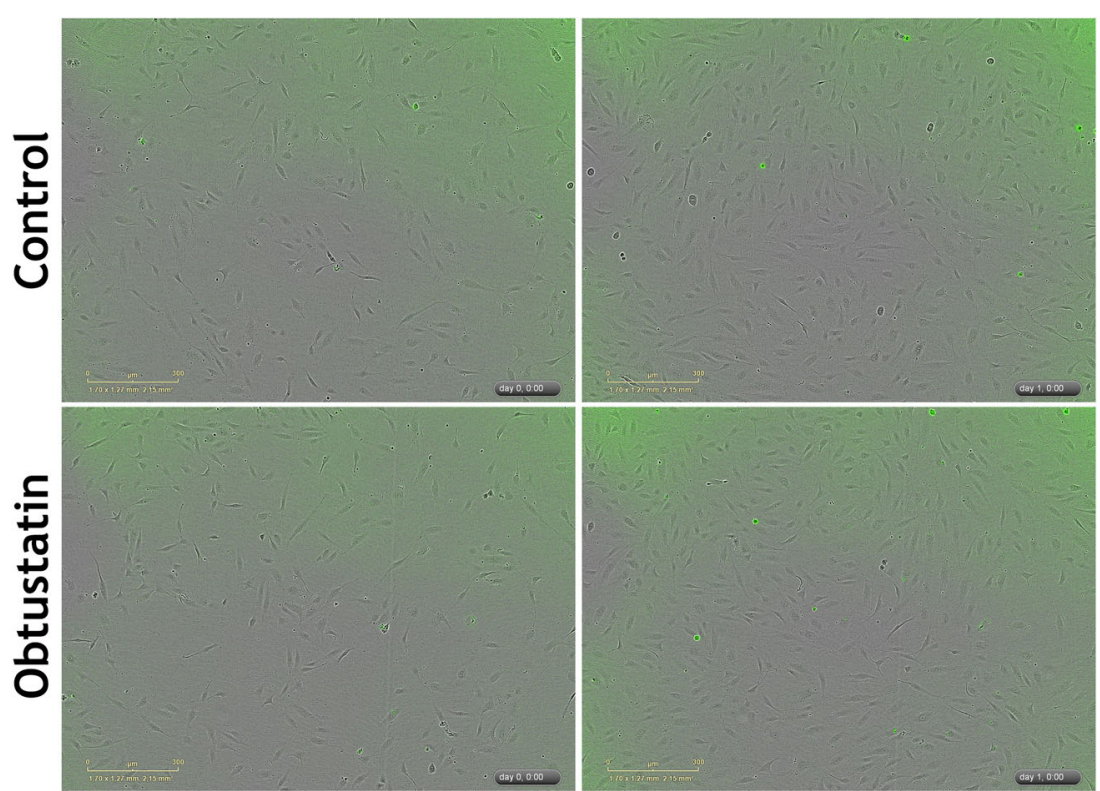

number of living cells. We found that pure obtustatin at the highest concentration of $90 \mu \mathrm{M}$ did not have any detrimental effect on endothelial cell viability (Fig. 5a). We found that activation of the apoptosis biomarker caspase 3/7 (whose activity is proportional to the luminescent signal produced following cleavage of a substrate containing the tetrapeptide sequence DEVD) was not increased in HMVEC-D cells treated with obtustatin (Fig. 5b). We found marginally higher apoptosis levels in control cells, possibly due to their higher proliferation rate.

\section{Discussion}

The importance of integrins and their receptors in different physiological and pathological conditions has been widely described [8, 19, 23, 31, 39-41]. $\alpha \mathrm{VB3}$ integrin receptor was initially identified as a putative target for inhibition of tumorinduced angiogenesis [17]. Recent studies suggest that other integrins may also be valuable targets, for example, $\alpha 1 \beta 1$,

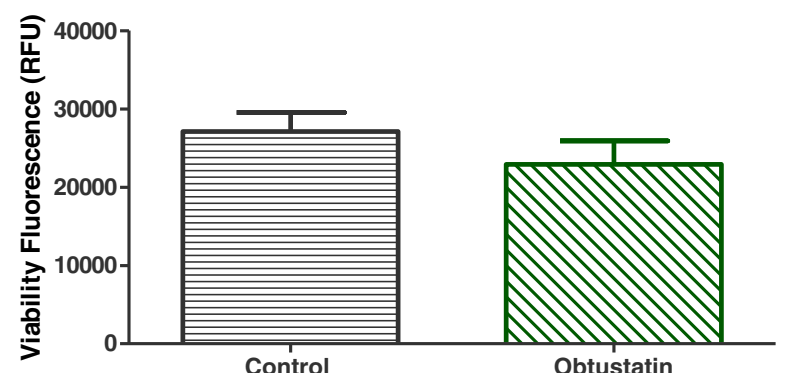

a

Fig. 5 ApoLive-Glo multiplex assay for HMVEC-D cell viability (a) and apoptosis (b). HMVEC-D cells induced to proliferate in the presence of human recombinant VEGF $(50 \mathrm{ng} / \mathrm{ml})$, were treated with obtustatin which has an important role in vessel neogenesis [18]. Obtustatin is a small peptide isolated from $M L O$ snake venom, shown to selectively inhibit the binding of $\alpha 1 \beta 1$ integrin to immobilized collagen. This low molecular weight peptide revealed a potent therapeutic effect on melanoma progression [4], and recently we have shown its inhibitory effect on S-180 sarcoma growth [16] without detectable toxicity as indicated by the absence of weight loss during the treatment. Hematoxyilineosin staining showed morphological changes in the obtustatin treated group compatible to necrosis and necrobiosis and exhibited significant reduction in the number of tumor cells. This prompted us to propose obtustatin as a potential therapeutic agent against sarcoma. Besides its action as a disintegrin, obtustatin targets additional anionic constituents of tumour cells, specifically genomic DNA [16]. However, the mechanism of action of obtustatin in sarcoma angiogenesis have not been previously studied.

In the present study we examined the expression of VEGF in our model after treatment as it is one of the most specific and pivotal regulators of the angiogenic signaling cascade [6,

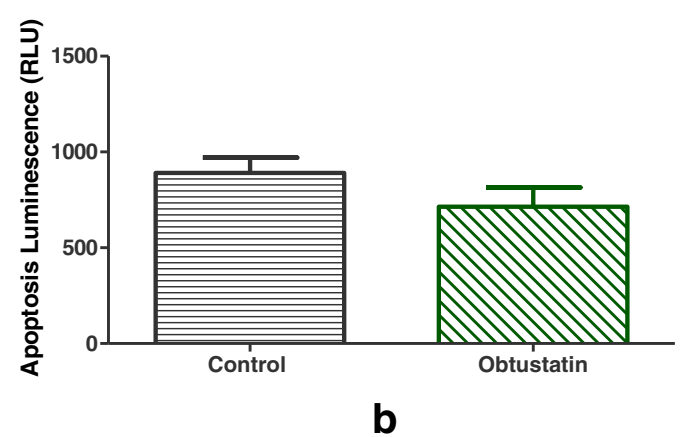

$(90 \mu \mathrm{M})$ for $24 \mathrm{~h}$. Values are mean \pm s.d. of three technical replicates. AFU, arbitrary fluorescence units; ALU, arbitrary luminescence units 
$7,12,15,26,30] .1 \mathrm{mg} / \mathrm{kg} /$ day obtustatin inhibited S-180 sarcoma tumor growth in mice by $33 \%$. At the same time, VEGF expression increased after treatment with obtustatin. This could be explained by the ability of obtustatin to inhibit angiogenesis which can cause hypoxia in the tumor tissue. Under hypoxic conditions hypoxia-inducible factor1- $\alpha$ (HIF-1 $\alpha$ ) is activated enhancing HIF- $1 \alpha$-dependent transcriptional activation of VEGF $[22,25,33,38]$. This hypothesis will be tested in the future by checking HIF- $1 \alpha$ expression in the control and treated group.

Accumulated evidence shows that several isolated or recombinant snake venom toxins exhibit anti-cancer effects in vitro and in vivo preclinical models, triggering cell death via the mitochondrial intrinsic apoptotic pathway or necrosis [1, 11, 32]. Our results revealed that obtustatin did not induce any signs of apoptotic death in the treatment of animals with sarcoma.

In previous studies by Brown et al. [4], an activation of the extrinsic apoptosis pathway was detected in vivo in a mouse experimental model of melanoma B16F 10 cells. However, we found no evidence of activation of caspase 8 for integrinmediated death (IMD) described previously [36]. It has also been shown that obtustatin does not induce apoptosis in vitro in the melanoma cell lines MV3 (human) and B16F10 (mouse) [4], although both cell lines express $\alpha 1 \beta 1$ integrin. It remains to be clarified whether the activation of the extrinsic pathway of apoptosis is an indirect effect through inhibition of angiogenesis in the melanoma xenograft model. In any case, we did not observe any indication of increased apoptosis in our sarcoma model.

In this study, we also evaluated the anti-angiogenic potential of obtustatin using the in vivo CAM assay. FGF2 was used to stimulate vessel growth, thus mimicking the pathologic scenario observed in solid tumors. We considered three parameters for vessel quantification: vessel diameter, vascular organization and directionality towards the inoculation site. We found that obtustatin inhibited FGF2 induced angiogenesis by $17 \%$.

Our results additionally demonstrated a lack of cytotoxicity of obtustatin in vitro, even for the extremely high concentration of $90 \mu \mathrm{M}$. However, this is a striking contrast with the previous study [4], which showed that $2 \mu \mathrm{M}$ of obtustatin efficiently killed $50 \%$ of the cells. A plausible explanation is the different source of obtustatin used in two studies, purified from venom at home laboratory vs. pure peptide (Tocris) in our case. Residual venom components could be responsible (alone or in association with obtustatin) for the apoptosis induction previously observed [4]. Thus, future work is needed in order to purify different protein fractions from the $M L O$ snake venom and identify peptides that synergize with obtustatin in angiogenesis inhibition.

Our research could provide a better understanding of the action mechanisms of obtustatin in STS to subsequently design a targeted therapy for this group of poorly responding tumors.

Funding This work was made possible by the research grant \# molbio 3440 from the Armenian National Science and Education Fund (ANSEF) based in New York.

\section{Compliance with ethical standards}

Conflict of interest The authors declare no conflict of interest.

Ethical approval All applicable international, national, and/or institutional guidelines for the care and use of animals were followed.

Informed consent For this type of study, formal consent is not required.

Publisher's note Springer Nature remains neutral with regard to jurisdictional claims in published maps and institutional affiliations.

\section{References}

1. Aranda-Souza M, Rossato F, Costa R, Figueira T, Castilho R, Guarniere M, Nunes E, Coelho L, Correia M, Vercesi AA (2014) Lectin from Bothrops leucurus snake venom raises cytosolic calcium levels and promotes B16-F10 melanoma necrotic cell death via mitochondrial permeability transition. Toxicon 2(82):97-103

2. Benassi MS, Gamberi G, Magagnoli G, Molendini L, Ragazzini P, Merli M, Chiesa F, Balladelli A, Manfrini M, Bertoni F (2001) Metalloproteinase expression and prognosis in soft tissue sarcomas. Ann Oncol 12:75-80

3. Bielenberg DR, Zetter BR (2015) The contribution of angiogenesis to the process of metastasis. Cancer J 21:267-273

4. Brown MC, Staniszewska I, Del Valle L, Tuszynski GP, Marcinkiewicz C (2008) Angiostatic activity of obtustatin as alphalbetal integrin inhibitor in experimental melanoma growth. Int J Cancer 123:2195-2203

5. Calvete JJ, Mureno-Murciano MP, Theakston DG, Kisiel DG, Marcinkiewicz C (2003) Snake venom disintegrins: novel dimeric disintegrins and structural diversification by disulphide bond engineering. Biochem J 372:725-734

6. Carmeliet P, Jain RK (2011) Principles and mechanisms of vessel normalization for cancer and other angiogenic diseases. Nat Rev Drug Discov 10:417-427

7. Carmeliet P, Jain RK (2000) Angiogenesis in cancer and other diseases. Nature 407:249-257

8. Chen X, Su Y, Fingleton B, Acuff H, Matrisian LM, Zent R, Pozzi A (2005) Increased plasma MMP9 in integrin a1-null mice enhances lung metastasis of colon carcinoma cells. Int J Cancer 116: $52-61$

9. Cormier JN, Pollock RE (2004) Soft tissue sarcomas. CA Cancer J Clin 54:94-109

10. Dean BJF, Whitwell D (2009) Epidemiology of bone and softtissue sarcomas. Orthop Traumatol 23:223-230

11. Ebrahim K, Shirazi F, Mirakabadi A, Vatanpour H (2015) Cobra venom cytotoxins; apoptotic or necrotic agents? Toxicon 108:134140

12. Ferrara N (2002) VEGF and the quest for tumour angiogenesis factors. Nat Rev Cancer 2:795-803

13. Fletcher CDM, Uni KK, Mertens F (2002) Eds: World Health Organisation classification of tumours. IARC Press, Pathology and genetics Lyon, $427 \mathrm{p}$ 
14. Folkman J (2002) Role of angiogenesis in tumor growth and metastasis. Semin Oncol 29:15-18

15. Folkman J (2003) Fundamental concepts of the angiogenic process. Curr Mol Med 3:643-651

16. Ghazaryan NA, Ghulikyan L, Kishmiryan A, Kirakosyan G, Nazaryan O, Ghevondyan T, Zakaryan N, Ayvazyan NM (2015) Anti-tumor effect investigation of obtustatin and crude Macrovipera lebetina obtusa venom in S-180 sarcoma bearing mice. Eur J Pharmacol 11:340-345

17. Golubkov V, Hawes D, Markland FS (2003) Anti-angiogenicactivity of contortrostatin, a disintegrin from Agkistrodoncontortrixcontortrix snake venom. Angiogenesis2003 6:213-224

18. Goswami S (2013) Importance of integrin receptors in the field of pharmaceutical \& medical science. Adv Biol Chem 3:224-252

19. Guimarães DO, Lopes DS, Azevedo FV, Gimenes SN, Silva MA, Achê DC, Gomes MS, Vecchi L, Goulart LR, Yoneyama KA, Rodrigues RS, Rodrigues VM (2017) In vitro antitumor and antiangiogenic effects of Bothropoidin, a metalloproteinase from Bothropspauloensis snake venom. Int J Biol Macromol 97:770-777

20. Hashizume H, Baluk P, Morikawa S, McLean JW, Thurston G, Roberge S, Jain RK, McDonald DM (2000) Openings between defective endothelial cells explain tumor vessel leakiness. Am J Pathol 156:1363-1380

21. Hedlund EM, Hosaka K, Zhong Z, Cao R, Cao Y (2009) Malignant cell-derived PlGF promotes normalization and remodeling of the tumor vasculature. Proc Natl Acad Sci U SA 106:17505-17510

22. Hirota K, Semenza GL (2006) Regulation of angiogenesis by hypoxiainducible factor 1. Crit Rev Oncol Hematol 59:15-26

23. Ibaragi S, Shimo T, Hassan NMM, Isowa S, Kurio N, Mandai H, Kodama S, Sasaki A (2011) Induction of MMP-13 expression in bone-metastasizing cancer cells by type I collagen through integrin a1b1 and a2b1-p38 MAPK signaling. Anticancer Res 31:13071313

24. Kisiel DG, Calvete JJ, Katzhendler J, Fertala A, Lazarovici P, Marcinkiewicz C (2004) Structural determinants of the selectivity of KTS-disintegrins for the alphalbeta1 integrin. FEBS Lett 577: $478-482$

25. Liang H, Xiao J, Zhou Z, Wu J, Ge F, Li Z, Zhang H, Sun J, Li F, Liu R, Chen $C$ (2018) Hypoxia induces miR-153 through the IRE $1 \alpha$-XBP1 pathway to fine tune the HIF $1 \alpha /$ VEGFA axis in breast cancer angiogenesis. Oncogene. https://doi.org/10.1038/ s41388-017-0089-8

26. Lijnen HR (2008) Angiogenesis and obesity. Cardiovasc Res 78: 286-293

27. Marcinkewicz C (2005) Functional characteristic of snake venom disintegrins: potential therapeutic implication. Curr Pharm Des 11: $815-827$

28. Marcinkiewicz C, Rosenthal LA, Mosser DM, Kunicki TJ, Niewiarowicz C (1996) Immunological characterization of erististatin and echistatin binding sites on $\alpha \operatorname{IIb} \beta 3$ and $\alpha v \beta 3$ integrins. Biochem J 317:817-825

29. Marcinkiewicz C, Weinreb PH, Calvete JJ, Kisiel DG, Mousa SA, Tuszynski GP, Lobb RR (2003) Obtustatin: a potent selective inhibitor of alphalbetal integrin in vitro and angiogenesis in vivo. Cancer Res 9:2020-2023

30. Naldini A, Carraro F (2005) Role of inflammatory mediators in angiogenesis. Curr Drug Targets Inflamm Allergy 4:3-8

31. Pozzi A, Moberg PE, Miles LA, Wagner S, Soloway P, Gardner HA (2000) Elevated matrix metalloprotease and angiostatin levels in integrin alpha 1 knockout mice cause reduced tumor vascularization. Proc Natl AcadSci USA 97:2202-2207

32. Prinholato da Silva C, Costa T, Paiva R, Cintra A, Menaldo D, Antunes L, Sampaio S (2015) Antitumor potential of the myotoxin BthTX-I from Bothrops jararacussu snake venom: evaluation of cell cycle alterations and death mechanisms induced in tumor cell lines. J Venom Anim Toxins Incl Trop Dis. https://doi.org/10.1186/ s40409-015-0044-5

33. Pugh CW, Ratcliffe PJ (2003) Regulation of angiogenesis by hypoxia: role of the HIF system. Nat Med 9:677-684

34. Sanz L, Ayvazyan N, Calvete JJ (2008) Snake venomics of the Armenian mountain vipers Macrovipera lebetina obtusa and Vipera raddei. J Proteome 71:198-209

35. Senger DR, Perruzzi CA, Streit M, Koteliansky VE, De Fougerolles AR, Detmar M (2002) The $\alpha 1 \beta 1$ and $\alpha 2 \beta 1$ integrins provide critical support for vascular endothelial growth factor signaling, endothelial cell migration, and tumor angiogenesis. Am J Pathol 160: 195-204

36. Stupack DG, Cheresh DA (2002) Get a ligand, get a life: integrins, signaling and cell survival. J Cell Sci 115:3729-3738

37. Vihinen P, Riikonen T, Laine A, Heino J (1996) Integrin alpha 2 beta 1 in tumorigenic human osteosarcoma cell lines regulates cell adhesion, migration, and invasion by interaction with type I collagen. Cell Growth Differ 7:439-447

38. Wang GL, Semenza GL (1993) Characterization of hypoxiainducible factor 1 and regulation of DNA binding activity by hypoxia. J Biol Chem 268:21513-21518

39. Wang YQ, Su J, Wu F, Lu P, Yuan LF, Yuan WE, Sheng J, Jin T (2012) Biscarbamate cross-linked polyethylenimine derivative with low molecular weight, low cytotoxicity, and high efficiency for gene delivery. Int J Nanomedicine 7:693-704

40. Yoshimura K, Meckel KF, Laird LS, Chia CY, Park JJ, Olino KL, Tsunedomi R, Harada T, Iizuka N, Hazama S (2009) Integrin a2 mediates selective metastasis to the liver. Cancer Res 69:7320 7328

41. Zhang Z, Ramirez NE, Yankeelov TE, Li Z, Ford LE, Qi Y, Pozzi A, Zutter MM (2008) a2b1 integrin expression in the tumor microenvironment enhances tumor angiogenesis in a tumor cell-specific manner. Blood 111:1980-1988 